\title{
EVALUACIÓN IN VITRO DEL EFECTO ANTIBACTERIANO DE LOS EXTRACTOS DE Bidens pilosa, Lantana camara, Schinus molle Y Silybum marianum
}

\section{IN VITRO EVALUATION OF THE ANTIBACTERIAL EFFECT OF Bidens pilosa, Lantana camara, Schinus molle AND Silybum marianum}

\author{
Anastasia Cruz-Carrillo1, Natalia Rodríguez N. ${ }^{2}$, Carlos Eduardo Rodríguez ${ }^{3}$
}

\begin{abstract}
${ }^{1}$ MV. Esp. MSc. Docente Programa MVZ, UPTC-Tunja. Grupo GICIVET anicata22@hotmail.com² MVZ UPTC. natamvz16@yahoo. com $^{3}$ Z. Esp. Docente Programa MVZ, UPTC-Tunja. Grupo GIBNA ceromol@hotmail.com
\end{abstract}

Rev. U.D.CA Act. \& Div. Cient. 13 (2): 117-124, 2010

\section{RESUMEN}

Uno de los temas más importantes de la medicina humana y veterinaria es la resistencia bacteriana a los antibacterianos. En este contexto, se ha estimulado la búsqueda de nuevos principios activos con actividad antibacteriana, por lo que el objetivo de este trabajo fue determinar las propiedades antibacterianas de cuatro especies vegetales, recolectadas en la ciudad de Tunja (Boyacá). Se prepararon extractos etanólicos, a partir de las hojas secas de Bidens pilosa, Lantana camara, Schinus molle y Silybum marianum, los cuales, fueron sometidos a un análisis microbiológico in vitro, para establecer su actividad antibacteriana y sus concentraciones mínimas inhibitoria y bactericida, en respuesta a Staphylococcus aureus, Escherichia coli y Pseudomona aeruginosa. Las actividades, se compararon con un fármaco estándar, cloranfenicol o gentamicina. Los extractos mostraron actividad contra S. aureus; la que exhibió la mejor actividad fue $B$. pilosa y $L$. camara, S. molle y $S$. marianum manifestaron capacidad moderada para inhibir el crecimiento de $S$. aureus. Este estudio demuestra que las plantas seleccionadas tienen actividad antibacteriana frente a S. aureus.

Palabras clave: Fitofarmacología, chipaca, cardo, lantana, pimentero.

\section{SUMMARY}

One of the most important subjects of human and veterinary medicine is the bacterial resistance to the anti-bacterial treatments. Against this background the search of new active principles with anti-bacterial activity has been stimulated, reason why the objective of this work was to determine the anti-bacterial properties of four vegetal species, collected in the city of Tunja (Boyacá). Etanólicos extracts from dry leaves of Bidens pilosa, Lantana camara, Schinus molle and Silybum marianum were prepared and submitted to a microbiologic in vitro test, to establish their anti-bacterial activity, their minimal inhibiting and bactericidal concentrations, in response to Staphylococcus aureus, Escherichia coli and Pseudomona aeruginosa. All activities were compared to a standard medicine, cloranfenicol or gentamicina. The extracts showed activity against $S$. aureus. B. pilosa exhibited the best activity, L. camara, S. molle and S. marianum, showed moderate capacity to inhibit $S$. aureus growth. This study demonstrated that the selected plants have anti-bacterial activity against $S$. aureus.

Key words: Phitopharmacology, chipaca, cardo, lantana, pimentero.

\section{INTRODUCCIÓN}

Uno de los temas que más preocupa a la comunidad científica en medicina humana y veterinaria es la constante emergencia de cepas bacterianas refractarias a uno o más antibacterianos, lo que constituye, actualmente, un problema creciente de salud pública a nivel mundial (OMS, 2001). La resistencia a los antibacterianos, se traduce en ineficacia de los tratamientos, generando un importante impacto en la salud y en la producción animal; adicionalmente, se seleccionan bacterias multi-resistentes de procedencia animal, que se pueden transmitir a la población humana (San Martín et al. 2005), constituyendo, entonces, un problema zoonótico. 
Frente a la velocidad con que las bacterias logran desarrollar la resistencia a los fármacos tradicionales, la producción de nuevas moléculas es lenta y ha disminuido, notoriamente, en los últimos años, por lo que acontecen casos contra los que no existe tratamiento eficaz (Soto, 2003; Domingo E López, 2003).

En respuesta a la necesidad de conseguir alternativas eficaces para el control de las infecciones bacterianas, se ha recurrido a la fitoquímica y fitofarmacológica, logrando encontrar nuevas moléculas (Ávila et al. 2006). Así, se acepta que a pesar del avance alcanzado por la síntesis química, las plantas son una valiosa fuente de sustancias activas con propiedades antibacterianas (Nascimento et al. 2000), apoyados en que éstas producen más de 100.000 metabolitos secundarios, muchos de los cuales pueden ser antibacterianos (Domingo E López, 2003).

Colombia es una región privilegiada por su biodiversidad, ya que cuenta con más de 40.000 especies vegetales, donde cerca del $10 \%$ se han investigado y reportan efectos fitoterapéuticos (Sánchez, 2006).

Hace diez años, se demostró que el extracto etanólico de Bidens pilosa ("amor seco", "chipaca") tiene actividad frente a Mycobacterium tuberculosis y M. smegmatis (Makabir, 1990). Posteriormente, en un estudio realizado en Colombia, se determinó que el extracto etanólico presentó moderada actividad frente a Staphylococcus aureus y Bacillus cereus (Rojas et al. 2006). También, se reporta que el extracto crudo de Bidens pilosa posee baja actividad ante Escherichia coli y S. aureus (Khan et al. 2001) y moderada sensibilidad, de su aceite esencial, contra la E. coli (Deba et al. 2007). La Lantana camara muestra actividad frente a Bacillus subtillis y S. aureus (Misra E Laatsch, 2000), aunque en otros estudios, los extractos clorofórmicos y hexánicos de la misma, no tuvieron efecto ante $S$. aureus y $E$. coli (Hernández et al. 2003). El extracto de diclorometano: metanol (1:1) de $L$. cámara demostró actividad frente $S$. aureus, pero no frente a E. coli y P. aeruginosa (Kumara et al. 2006). Por otro lado, en un análisis de las fracciones de cloroformo y de metanol de la planta, se determinó mayor acción frente a bacterias Gram positivas y que el extracto metanólico inhibía a $P$. aeruginosa (Basu et al. 2005). En otro ensayo, se estableció que el ácido lantánico tiene actividad contra B. cerus y E. coli (Saleh et al. 1999).

Una investigación afirma que el aceite esencial de Schinus molle ("molle", "pimentero") muestra actividad ante bacterias como: S. aureus, Klebsiella, pneumoniae, Pseudomona aeruginosa, Enterobacter aerogenes, Phaseolus vulgaris, Clostridium sporogenes, E. coli, Serratia marcescens, entre otras (Gundidza, 1993) y algunas cepas resistentes de Streptococcus pneumoniae presentan sensibilidad al extracto hexánico de Schinus molle (Molina et al. 2007). Por último, un estudio definió que la silibina derivada del Silybum marianum ("cardo", "cardo blanco") inhibe la síntesis de RNA y, por ello, de proteínas en bacterias Gram positivas (Lee et al. 2003). Se ha reportado que los flavolignanos (silibina, silicristina, silidianina y silimarina) poseen actividad antibacteriana y potencian la acción de sustancias antimicrobianas (Kurkin et al. 2001; Guz et al. 2001).

Frente a la existencia de plantas con metabolitos con actividad antibacteriana, el objetivo del presente trabajo fue identificar la actividad antibacteriana in vitro de los extractos etanólicos de cuatro plantas, determinando su concentración mínima inhibitoria (CMI) y su concentración mínima bactericida (CMB), para determinar la presencia de propiedades antibacterianas en estas especies vegetales, localizadas en el departamento de Boyacá.

\section{MATERIALES Y MÉTODOS}

En el presente estudio, se evaluó la actividad antibacteriana de los extractos etanólicos de B. pilosa, L. camara, S. molle y S. marianum, localizadas en el departamento de Boyacá, frente a tres cepas bacterianas patógenas: S. aureus, Escherichia. coli y $P$. aeruginosa. El experimento, se desarrolló en dos fases: la primera, relacionada con la preparación de los extractos vegetales, que se llevó a cabo en el Laboratorio de Control Biológico, perteneciente a la Facultad de Ciencias Agropecuarias de la Universidad Pedagógica y Tecnológica de Colombia (Tunja) y, la segunda, relacionada con la aplicación de las pruebas microbiológicas, tratada en uno de los laboratorios de microbiología de la Universidad de Boyacá (Tunja).

Material vegetal y obtención de los extractos. La recolección del material vegetal de las cuatro plantas evaluadas, se realizó en la ciudad de Tunja (Boyacá), veinte días antes de iniciar la fase experimental (febrero de 2008). Tunja está localizada a 2775 msnm, a $5^{\circ} 32^{\prime} 7^{\prime \prime}$ de latitud norte y a $73^{\circ} 22^{\prime} 04^{\prime \prime}$ oeste y presenta una temperatura promedio de $16^{\circ} \mathrm{C}$ y humedad relativa de $66 \%$. Las especies colectadas fueron identificadas; posteriormente las hojas de cada planta, se secaron a temperatura ambiente, durante ocho días en un lugar seco bajo cubierta y se trituraron manualmente, logrando una cantidad de $70 \mathrm{~g}$ de cada una. El material triturado fue sometido a un proceso de extracción alcohólica, con la técnica de Soxhlet (durante 48 horas), aplicado etanol 98\% destilado. El extracto etanólico obtenido en este proceso, se filtró e inmediatamente, se concentró en el rotaevaporador a presión reducida y temperatura constante de $80^{\circ} \mathrm{C}$ (punto de ebullición del etanol). Una vez evaporado el solvente, se obtuvo el extracto bruto de cada planta, que fue almacenado a $4^{\circ} \mathrm{C}$ hasta el momento de su utilización. Los extractos, finalmente, 
se evaluaron con cromatografía en capa fina, para determinar si el proceso extractivo había sido exitoso.

Pruebas microbiológicas. Se trabajó con cepas bacterianas de referencia de $E$. coli, $S$. aureus y $P$. aeruginosa, donadas por el Cepario del Departamento de Microbiología de la Universidad de Boyacá. Inicialmente, se efectuó la siembra, por aislamiento de las cepas de $E$. coli y $P$. aeruginosa, en agar MacConkey y $S$. aureus, en agar sangre, incubándose por 24 horas a $37^{\circ} \mathrm{C}$. Las cepas aisladas, se inocularon en agar nutritivo, mediante una siembra en estría, dos cultivos por cada bacteria, y se incubaron por 24 horas a $37^{\circ} \mathrm{C}$. Todos los cultivos se conservaron en refrigeración, a $4^{\circ} \mathrm{C}$.

A partir de las bacterias cultivadas en el agar nutritivo fueron seleccionadas cuatro o cinco colonias de cada una y se diluyeron en solución salina, hasta alcanzar una turbidez igual a la del tubo 0,5, de la escala de MacFarland. Luego, se efectuó una siembra masiva sobre agar Mueller Hinton, se colocaron los sensidiscos de cefalexina, cloramfenicol, gentamicina, norfloxacina, oxitetraciclina, piperacilina, ceftazidime, oxacilina, penicilina G, tobramicina, y trimetoprimsulfametoxazol y se procedió a la incubación, a $37^{\circ} \mathrm{C}$ por 24 horas, para observar la presencia de halos de inhibición (Sánchez, 1998). De este procedimiento, se escogieron el cloranfenicol, como control positivo para S. aureus y gentamicina, para $E$. coli y $P$. aeruginosa.

Evaluación de la actividad de los extractos. La actividad antibacteriana de cada extracto, se determinó por dos métodos: difusión en pozo (perforación en gel de agar) (Álvarez et al. 2005) y difusión en disco (método disco-placa-cultivo) (Udayakumar \& Hazzena, 2002). En el medio Mueller Hinton, ya solidificado, se hicieron cinco perforaciones de $11 \mathrm{~mm}$ de diámetro, con un sacabocados y se sellaron con $0,1 \mathrm{~mL}$ del mismo agar, para evitar la dispersión del extracto. Las cepas diluidas de la misma forma que en el antibiograma, se sembraron masivamente $y$, una vez realizado esto, a cada pozo se le adicionó $0,2 \mathrm{~mL}$ de cada extracto puro y $0,2 \mathrm{~mL}$ de agua destilada, como control negativo y se incubó a $37^{\circ} \mathrm{C}$, por 24 horas.

En la difusión en disco, las cepas diluidas se sembraron masivamente sobre el agar y se colocaron en la superficie del medio cinco discos de papel de filtro (Whatman) de $6 \mathrm{~mm}$ de diámetro, impregnados con $0,2 \mathrm{~mL}$ de cada uno de los extractos puros y agua destilada, como control negativo y se incubaron a $37^{\circ} \mathrm{C}$, por 24 horas. Ambas pruebas, se efectuaron por triplicado. Posteriormente, se midió el diámetro del halo de inhibición del crecimiento de los microorganismos y el cálculo del porcentaje del efecto inhibitorio relativo respecto al control positivo, que se procedió aplicando la siguiente expresión (Martínez, 1996):

$$
\begin{gathered}
\text { \% efecto } \\
\text { inhibitorio }
\end{gathered} \quad \begin{gathered}
\text { Media diámetro halo de inhibición } \\
\text { Diámetro halo de inhibición } \\
\text { control positivo }
\end{gathered}
$$

Concentración mínima inhibitoria. La concentración mínima inhibitoria (CMI), se aplicó para determinar la menor concentración de cada uno de los extractos que inhibe el crecimiento de las bacterias objeto de estudio. Para montar esta prueba, inicialmente, se prepararon diluciones madre de los extractos puros en agua destilada, correspondientes a 0,1/10; 0,3/10; 0,5/10; 0,8/10 y1/10 (Gonzáles et al. 1980), de cada uno de éstos. Se tomaron $02 \mathrm{~mL}$, para la técnica de perforación en gel de agar y $1 \mathrm{~mL}$, para la dilución en el medio de cultivo (Martínez et al. 2000). La CMI, se efectuó por triplicado.

En el primer método, se prepararon cinco cajas de Petri con agar Muller-Hinton y con cinco perforaciones de $11 \mathrm{~mm}$ de diámetro, cuatro para los extractos y una para el control negativo. En los pozos, se añadieron alícuotas de $0,2 \mathrm{~mL}$ de las diluciones madre de los extracto, de tal forma que, en cada caja, se evaluaba una concentración diferente, para los respectivos extractos (Tabla 1). Finalmente, estas se inocularon e incubaron a $37^{\circ} \mathrm{C}$, por 24 horas y se examinó la actividad antimicrobiana de las diferentes diluciones.

El procedimiento de dilución en medio de cultivo (determinación de la sensibilidad de una bacteria frente a un antibacteriano), se hizo según lo indicado por Struthers $\&$ Westran (2005). En principio, se preparó una suspensión bacteriana de cada una de las cepas, en solución salina y se incubaron a $37^{\circ} \mathrm{C}$, por 18 horas; luego, $4 \mathrm{~mL}$ de dichas suspensiones se agregaron, cada una a un matraz, con $50 \mathrm{~mL}$ de caldo nutritivo y se incubó a $37^{\circ}$, por 18 horas. A partir de este cultivo, se tomó una alícuota de $0,1 \mathrm{~mL}$, que se pasaron a tubos de ensayo, con $2 \mathrm{~mL}$ de caldo nutritivo y con $1 \mathrm{~mL}$ de cada una de las diluciones de los extracto (Tabla 2). Inmediatamente, se montaron las pruebas; $1 \mathrm{~mL}$ de la mezcla de cada tubo, se leyó en el espectofotómetro a $650 \mathrm{~nm}$, para determinar la absorbancia y, posteriormente, los tubos con la muestra restante, se incubaron por 18 horas, a $37^{\circ} \mathrm{C}$. Cumplido el tiempo, se hizo la lectura correspondiente en el espectrofómetro, determinando si la absorbancia había aumentado (hubo crecimiento bacteriano) o se había mantenido (hubo inhibición) y, de esta forma, se pudo establecer la CMI.

Concentración mínima inhibitoria o bactericida. En definitiva, una gota de los tubos que no presentaban turbidez, se cultivó en agar nutritivo para determinar la concentración mínima bactericida (CMB), con el fin de establecer a qué concentración fueron inhibidos los microorganismos del 
Tabla 1. Resultados de la actividad de los extractos de cuatro plantas sobre S.aureus, con la prueba de difusión en disco y en pozo.

\begin{tabular}{|c|c|c|c|c|c|c|c|c|}
\hline \multirow{2}{*}{ TÉCNICA } & \multicolumn{7}{|c|}{ DIÁMETRO DEL HALO DE INHIBICIÓN } \\
\cline { 2 - 9 } & \multicolumn{6}{|c|}{ Réplicas con Técnica Difusión en Disco } & \multicolumn{3}{c|}{ Réplicas con Técnica Difusión en Pozo } \\
\cline { 2 - 9 } & 1 & 2 & 3 & Promedio & 1 & 2 & 3 & Promedio \\
\hline $\begin{array}{c}\text { Lantana camara } \\
\text { Sylibum }\end{array}$ & 13 & 9 & 10 & $\mathbf{1 0 , 6 6}$ & 22 & 16 & 20 & $\mathbf{1 9 , 3 3}$ \\
\hline marianum & - & - & - & - & - & - & - & - \\
\hline Bidens pilosa & 20 & 15 & 18 & $\mathbf{1 7 , 6 6}$ & 31 & 30 & 31 & $\mathbf{3 0 , 6 6}$ \\
\hline Schinus molle & 11 & 10 & 10 & $\mathbf{1 0 , 3 3}$ & 28 & 26 & - & $\mathbf{2 7}$ \\
\hline
\end{tabular}

inóculo inicial, pero no fueron destruidos por la sustancia evaluada (Struthers \& Westran, 2005).

Para realizar el análisis estadístico de los datos, se aplicó ANOVA unifactorial; la prueba de Levene, para igualdad de varianzas; el test de t Student, para muestras relacionadas y el test T, para muestras independientes. La significancia, se reportó con un nivel de confianza del 95\% $(p=0,05)$. Para realizar estos cálculos, se empleó el programa estadísticos SPSS 13.0.

\section{RESULTADOS Y DISCUSIÓN}

Los extractos etanólicos de las hojas de L. camara, S. marianum, B. pilosa y S. molle mostraron actividad inhibitoria contra Staphylococcus aureus, comprobado por los diversos métodos aplicados en este estudio. Por el contrario, al realizar el enfrentamiento de las cepas de E. coli y $P$. aeruginosa se evidenció que éstas no fueron sensibles ante ninguno de los extractos ensayados en todas las pruebas. Se puede suponer que los extractos etanólicos de las plantas, objeto de estudio, no tienen actividad sobre bacterias Gram negativas, posiblemente, porque las bacterias Gram negativas presentan compuestos anfipáticos que operan como bombas de expulsión de diversas sustancias, por lo cual, el antibacteriano es expulsado de manera inmediata, sin alcanzar a cumplir el efecto (Domingo \& López, 2003). Otras posibles explicaciones corresponden a la posibilidad que el compuesto activo no alcance el sitio blanco de acción o bien, la estructura de las porinas impida el paso del principio activo al interior de la célula bacteriana (Soto, 2003). Este hallazgo difiere de lo reportado por otros autores, quienes indican que los extractos etanólicos de Chipaca (B. pilosa) y de $L$. cámara, tienen efecto contra E. coli (Rojas et al. 2006; Samy \& Ignacimuthu, 2000; Valsaraj et al. 1997).

Evaluación de la actividad antibacteriana. Las pruebas de actividad antibacteriana realizadas por los métodos de difusión en disco y difusión en pozo mostraron que los extractos $B$. pilosa, $L$. camara y S. molle presentan actividad antimicrobiana frente a $S$. aureus, mientras que el extracto de S. marianum no reveló acción ante esta bacteria, en ninguna de las tres réplicas. De acuerdo con el promedio del diámetro del halo de inhibición, se estableció que la actividad del extracto de Bidens pilosa fue alta y la de los extractos de $L$. camara y S. molle fue media (Tabla 1). Este resultado concuerda con lo publicado por Sharm E Kumar (2009), quienes reportaron actividad de la $L$. cámara contra $S$. aureus, debida a la alta presencia de flavonoides en la misma. Igualmente, Barre et al. (1997), identificaron, desde ese año, el efecto de esta planta contra la mencionada bacteria y contra Salmonella typhi, debido a la presencia del ácido lantanólico, propio de la planta. Al contrastar la actividad de los extractos $(p>0,05)$, tanto en la difusión en disco, como en la difusión en pozo, se hallaron diferencias significativas, cuando se comparó la actividad del extracto de $B$. pilosa frente a los de $L$. camara y $S$. molle. Al enfrentar la acción de $L$. camara y $S$. molle no se percibieron diferencias significativas, es decir, su espectro de efectividad fue muy similar. 
El porcentaje de inhibición relativa de los extractos de $L$. camara y S. molle fue $70,1 \%$ y $63,1 \%$, en la prueba de difusión en pozo, mientras que en la de difusión en disco fueron de $56,1 \%$ y 54,3\%, respectivamente. La actividad del extracto de $B$. pilosa fue $129,8 \%$ y $92,9 \%$, en los test referidos anteriormente. Una acción antibacteriana se considera alta cuando su porcentaje de inhibición relativo es $>70 \%$, intermedia entre el 50-70\% y baja cuando es <50\% (Ramírez $\mathcal{E}$ Díaz, 2007). En consecuencia, en ambas pruebas, el extracto de $B$. pilosa presentó actividad alta, mientras que $L$ camara y S. molle mostraron actividad intermedia.

Al comparar el porcentaje de inhibición relativo calculado para cada extracto, en ambos protocolos, se evidencia que en la prueba de difusión en pozo los extractos exhiben mejor desempeño con relación a la difusión en disco, lo que concuerda con la literatura, donde se indica que la adición de los extractos en pozos realizados en el agar, concentra y difunde mayor cantidad de éste, facilitando la evaluación de su potencial antibacteriano (Vlachos et al. 1997; 1996).

Por otra parte, el extracto etanólico de $B$. pilosa reveló actividad antibacteriana comparable con la del fármaco patrón (cloranfenicol), lo cual, contradice lo señalado por Rojas et al. (2006), quienes encontraron por el método de difusión en disco $66,7 \%$, como porcentaje de inhibición relativa del extracto etanólico de la chipaca frente a S. aureus.

Se ha reportado que el extracto etanólico de L. camara, evaluado por la técnica de difusión en disco, posee actividad alta contra $S$. aureus con halos de inhibición de 14,6 y 14,8mm (Gelera et al. 1998). En contraposición a este postulado, en esta investigación, se pudo encontrar efectividad intermedia ante $S$. aureus con zonas de inhibición de $10,6 \mathrm{~mm}$, en promedio. Para S. molle no se apreciaron estudios donde se caracterice la actividad del extracto etanólico; sin embargo, se reportó que el extracto metanólico no muestra actividad ante S. aureus (Molina et al. 2007). Dado que el metanol y el etanol tienen una polaridad muy parecida (alta), extraen un rango de compuestos similares (Brewster, 1978); con base en esto, se puede sugerir que a diferencia de lo expresado por Molina et al. (2007), S. molle tiene capacidad para inhibir el crecimiento de $S$. aureus. Con respecto a $S$. marianum, se ha citado que la silibina presente en los extractos tiene actividad contra bacterias Gram positivas (Lee et al. 2003).

Evaluación de la CMI de los extractos. Al determinar la CMI con la técnica de la dilución en caldo, se observó que el extracto S. marianum mostró actividad antibacteriana frente a S. aureus; no obstante, su efecto se da a una concentración alta $(21 \mathrm{mg} / \mathrm{mL})$ respecto a los otros extractos. El extracto S. molle inhibió a una concentración de $18 \mathrm{mg} / \mathrm{mL}$ y los extractos $L$. camara y $B$. pilosa actuaron a una concentración de $12 \mathrm{mg} / \mathrm{mL}$, siendo esta última la más baja. La CMI en tubo (dilución en caldo, se considera como el parámetro fundamental para comprobar la sensibilidad de una bacteria frente a un antibacteriano (Struthers $\&$ Westran, 2005). Por tal razón, es la técnica más confiable para determinar las propiedades antimicrobianas de una sustancia. Al someter los cuatro extractos a la dilución en el medio de cultivo, se pudo establecer que todos presentaron actividad frente a S. aureus. De acuerdo con lo descrito por Avellaneda et al. (2005), una cepa bacteriana es muy sensible cuando la sustancia evaluada presenta una CMI inferior a $12,5 \mathrm{mg} / \mathrm{ml}$, de mediana sensibilidad, entre 12,5 y $50 \mathrm{mg} / \mathrm{mL}$ y de baja sensibilidad cuando la CMI está entre 50 a 100mg/mL.

Según esta escala, $S$. aureus exhibió alta sensibilidad frente a los extractos etanólicos de $B$. pilosa y $L$. camara, mientras que ante $S$. molle y $S$. marianum, sensibilidad intermedia. El extracto que actuó a mayor concentración respecto a los demás fue el de $S$. marianum. Se deduce, que el resultado negativo en la difusión en las dos técnicas, se puede deber a que las sustancias con actividad antibacteriana se encuentran en bajas concentración (Ávila et al. 2006). Para los grupos correspondientes a las menores concentraciones de los extractos evaluados (dilución de 0,5), el valor de p, según el test $t$, fue $>0,05$, indicando que no hubo diferencias significativas entre la absorbancia pre-incubación y la postincubación, para estas muestras, por lo que los extractos, en sus concentraciones más bajas, no generaron inhibición del crecimiento de $S$. aureus. Los otros grupos (diluciones de 0,3 en adelante) mostraron un valor de $p<0,05$, lo que significa que hubo diferencia significativa entre las absorbancias pre y post incubación, como consecuencia de la disminución de éstas después de la incubación, debida a la acción de cada uno de los extractos; así, se puede corroborar que los extractos etanólicos de B. pilosa, L. camara, S. molle y S. marianum, ejercieron acción inhibitoria frente a $S$. aureus.

En un estudio realizado con otras especies vegetales, se determinó que en la técnica de CMI en tubo, el $S$. aureus fue inhibido por los extractos alcohólicos de las hojas de Austroeupatorium inulaefolium, 50mg/mL y Ludwigia polygonoides, 25mg/mL (Álvarez et al. 2005).

Buscando corroborar el efecto de las plantas sobre S. aureus, se efectuó la CMI por perforación en gel de agar y se confirmó la ausencia de actividad del extracto de $S$. marianum. Para los extractos $L$. camara y $B$. pilosa, la CMI fue de 2,4mg/0,2mL, para el extracto de $S$. molle de 9,6mg/0,2mL. Las medias de los diámetros de los halos de inhibición que se presentaron al evaluar las diferentes concentraciones de los extractos se compararon, para determinar la relación actividadconcentración (Tabla 2). Con ello se logró evidenciar una relación directamente proporcional entre la concentración del 
extracto y el diámetro de la zona de inhibición. También, se pudo observar que aunque $L$. camara y $B$. pilosa actuaron a la misma concentración, la actividad de la primera fue menor (diámetro del halo $=12 \mathrm{~mm}$ ), basado en que la actividad es baja cuando el halo está entre 12-18mm (Nascimento et al. 2000). Teniendo en cuenta los mismo autores, se considera como actividad media cuando el halo está entre 17 y 26mm, por lo que la $B$. pilosa, en este estudio, mostró actividad dentro de ese rango, con diámetro del halo de $18 \mathrm{~mm}$. Por lo tanto, $B$. pilosa tuvo mejor actividad que L. camara y S. molle al actuar a mayor concentración $(9,6 \mathrm{mg} / 0,2 \mathrm{~mL})$ (Tabla 2$)$.

Tabla 2. Concentración mínima inhibitoria obtenida con los extractos de cuatro plantas mediante dos técnicas.

\begin{tabular}{|c|c|c|c|c|c|c|c|c|c|c|}
\hline \multirow{2}{*}{ TÉCNICA } & \multicolumn{4}{|c|}{ Técnica de Perforación en Gel } & \multicolumn{5}{c|}{ Técnica de Difusión en Pozo } \\
\cline { 2 - 13 } & \multicolumn{4}{|c|}{ Concentración (mg/0,2mL) } & \multicolumn{5}{c|}{ Concentración (mg/mL) } \\
\cline { 2 - 13 }$y$ & 0,1 & 0,3 & 0,5 & 0,8 & 1 & 0,1 & 0,3 & 0,5 & 0,8 & 1 \\
\hline Lantana camara & 0,8 & 2,4 & 5,6 & 6,4 & 13,4 & 4 & 12 & 28 & 32 & 67 \\
\hline Sylibum marianum & 1,4 & 4,2 & 7,6 & 11,2 & 16 & 7 & 21 & 38 & 56 & 80 \\
\hline Bidens pilosa & 1,4 & 2,4 & 5,6 & 6,4 & 13,4 & 7 & 12 & 28 & 32 & 67 \\
\hline Schinus molle & 1,2 & 3,6 & 4,4 & 9,6 & 14,4 & 6 & 18 & 22 & 48 & 72 \\
\hline
\end{tabular}

Concentración mínima bactericida. La CMB expresada en $\mathrm{mg} / \mathrm{mL}$ fue 38, 28, 22 y 12 para $S$. marianum, $L$ camara, $S$. molle y $B$ pilosa, respectivamente, con lo que se determinó que $B$. pilosa presentó alta actividad letal frente a $S$. aureus, $(\mathrm{CMB}=<20 \mathrm{mg} / \mathrm{ml})$ (Avellaneda et al. 2005), mientras que los extractos $L$. camara, S. molle yS. marianum exhibieron, acción intermedia ( $C M B=20-50 \mathrm{mg} / \mathrm{mL}$ ) (Avellaneda et al. 2005).

Se concluye, que el extracto etanólico de B. pilosa demostró ser muy activo frente a $S$. aureus. Al confrontarlo con el cloranfenicol evidenció una acción comparable e, incluso, mejor que la de este antibiótico. Esto difiere de lo manifestado en otros estudios, donde reportaron una moderada actividad del extracto de esta especie vegetal, frente a $S$. aureus (Rojas et al. 2006; Khan et al. 2001). En otros trabajos, se encuentra que el extracto presenta leve actividad ante $E$. coli (Chang et al. 2007; Khan et al, 2001), pero en esta investigación no se detectó sensibilidad.

La eficacia encontrada con el extracto etanólico de $L$. camara concuerda con otros estudios, donde se concluye que los extractos metanólicos, clorofórmicos, de diclorometanometanol y el aceite esencial de esta planta, tienen una actividad contra bacterias Gram positivas (B. cereus y $S$. aureus) (Basu et al. 2005; Misra E Laatsch, 2000). A diferencia de lo señalado por Basu et al. (2005), en este estudio el extracto no inhibió a P. aeruginosa. Según Hernández et al. (2003), los extractos elaborados a partir de etanol, hexano, cloroformo y la mezcla de diclorometano-metanol no tienen actividad ante S. aureus. Según Kumara et al. (2006) esta planta tiene un efecto inhibitorio alto frente a $S$. aureus, pero en este trabajo fue intermedia. Aunque en otras investigaciones esta planta se reporta como eficaz ante bacterias Gram negativas (Valsaraj et al. 1997; Samy \& Ignacimuthu, 2000), en este estudio, igual que en otros trabajos (Rajakaruna et al. 2002), los extractos de esta planta fueron ineficaces. Este mismo autor referenció que el extracto de la sanguinaria ( $L$. camara) mostró una actividad fotoinducida ante $P$. aureginosa, generando halos de inhibición entre 8-9,9mm (Rajakaruna et al. 2002). Utilizando mayor concentración del extracto, como se hizo con la prueba de CMI en tubo, se observó mejor actividad.

La cepa de $S$. aureus presentó una sensibiliad intermedia (en todos los test) frente al extracto etanólico de S. molle. Se ha señalado que el aceite esencial tiene efecto sobre $S$. aureus, E. coli y $P$. aureginosa (Gundidza, 1993), en este sentido es importante mencionar que el extracto etanólico es una mezcla total, que tiene en su composición una gran variedad de sustancias incluyendo algunos aceites, bajo esta perspectiva hay coincidencia respecto al espectro de acción ante $S$. aureus, pero los resultados de este proyecto difieren en cuanto a la acción contra $E$. coli y $P$. aureginosa. 
Con los resultados obtenidos en este trabajo, se pudo encontrar que los extractos etanólicos obtenidos, a partir de las hojas de B. pilosa, L. camara, S. molle y S. marianum, no tuvieron actividad in vitro frente a E.coli y $P$. aeruginosa. Sobre el $S$. aureus, el extracto de $B$. pilosa fue el que tuvo mayor acción antibacteriana y se catalogó como bactericida. Los demás extractos presentaron un comportamiento de tipo bacteriostático. Las plantas estudiadas, en particular $B$. pilosa, por la actividad demostrada ante $S$. aureus, pueden constituir una alternativa contra bacterias Gram positivas. Por los resultados alcanzados, se puede afirmar que $B$. pilosa, L. camara, S. molle y $S$ marianum son especies vegetales promisorias del departamento de Boyacá. Se sugiere continuar evaluando las plantas medicinales en busca de aquellas con actividad antibacteriana y, posteriormente, identificar y aislar los metabolitos secundarios causantes de tal efecto.

Agradecimientos. Los autores del trabajo manifiestan sus agradecimientos al Laboratorio de Control Biológico de la FACIAT, UPTC y a la Universidad de Boyacá, por el soporte prestado para desarrollar el proyecto. Conflicto de intereses. El presente manuscrito fue estructurado y revisado por todos los autores, quienes declaramos que no existe ningún conflicto de intereses que ponga en riesgo la validez de los resultados presentados.

\section{BIBLIOGRAFÍA}

1. ÁLVAREZ, M.; IZASA, M.; ECHEVERRY, H. 2005. Efecto antibacteriano in vitro de Austorcupatorium inulaefolium HBK (salvia amarga) y Ludwigia polygonoides HBK (clavo de laguana). Biosalud. 14:46-55.

2. AVELLANEDA, S.; ROJAS, N.; CUÉLLAR, A.; FONSECA, R. 2005. Actividad antibacteriana de Diphysa minutifolia Rose. Rev Cubana de Plant Med. 10(2):42-47.

3. ÁVILA, L.; BAQUERO, E.; VIÑA, A.; MURRILLO, E. 2006. Actividad antibacteriana de Diplostephium tolimense Cuatrec. (Asteraceae) frente a Staphylococcus aureus. Vitae. 3(1):55-60.

4. BARRE, J.T.; BOWDEN, B.F.; COLL, J.C.; De JESUS, J.; De La FUENTE, D.E.; JANAIRO, G.C.; RAGASA, C.Y. 1997. A bioactive triterpene from Lantana cámara. Phytochemistry. 45(2):321-324.

5. BASU, S.; GHOSH, A.; HAZRA, B. 2005. Evaluation of the antibacterial activity of Ventilago madraspatana Gaertn, Rubia cordifolia Linn. and Lantana camara Linn: isolation of emodin and physcion as active antibacterial agents. Phytotherapy Res. 19(1):888-894.
6. BREWSTER, R. 1978. Curso de química orgánica experimental. Ed. Alhambra. México. 43p.

7. CHANG, S.; CHIANG, Y.; YEN, H.; SHYUR, L.; WU, T.; YANG, C. 2007. Flavonoids, centaurein and centauredin from Bidens pilosa, stimulate IFN_expresion. J. Ethnopharmacology. 112:232-236.

8. DEBA, F.; XUAN, T.; YASUDA, M.; TAWATA, S. 2007. Chemical composition and antioxidant, antibacterial and antifungal activities of the essential oils from Bidens pilosa Linn. var. radiata. Food Control. 19:346-352.

9. DOMINGO, D.; LÓPEZ, M. 2003. Plantas con acción antimicrobiana. Rev Española Quimioterapia. 16(4):385-393.

10. GELERA, G.; BRILLATE, E.; ALIX, M.; PASADILLA, R.; AGHA, B.; MÁRQUEZ, M.; REYES, E. 1998. Antibacterial activity of $L$. cámara leaf extracs. Philippine Society for Microbiology. Proc. 27 ${ }^{\text {th }}$ Annual Convention Philippine Soc. Microbiol. Inc. Manila (Philippines). p.270-274.

11. GONZÁLES, F.; GREEN, G.; FLORES, F. 1980. Observaciones al microscopio electrónico de barrido de la acción del extracto acuoso de la esponja Haliclona sp. sobre Staphylococcus aureus. VI Congreso Nal Oceanografía, Ensenada B. California, México. 27p.

12. GUNDIDZA, M. 1993. Antimicrobial activity of essential oil from Schinus molle. Centr. Africa J. Med. 39(11):231-234.

13. GUZ, N.; STERMITZ, J.; JHONSON, T.; BEESON, S.; WILLEN, S.; HSIANG, J.; LEWIS, K. 2001. Flavonolignan and flavone inhibitors of a Staphylococcus aureus multidrug resistance pump: structure-activity relationships. J. Med Chem. 44:261-268.

14. HERNÁNDEZ, T.; CANALES, M.; ÁVILA, J.; DURÁN, A. 2003. Ethnobotany and antibacterial activity of some plants used in traditional medicine of Zapotitlán de las Salinas, Puebla (México). J. Ethnopharmacology. 88:181-188.

15. KHAN, M.; KIARA, M.; OMOLOSO, A. 2001. Anti-microbial activity of Bidens pilosa, Bischofia ja_anica, Elmerillia papuana and Sigesbekia orientalis. Fitoterapia. 72:662-665.

16. KUMARA, P.; CHAUHANA, S.; PADHA, H.; RAJANI, M. 2006. Search for antibacterial and antifungal agents from selected Indian medicinal plants. J. Ethnopharmacology. 107:182-188. 
17. KURKIN, V.; VOLOTSUEVA, A.; AVDEEVA, E. 2001. Flavolignans of Silybum marianum Fruit. Chem. Natural Compounds. 37(4):315-317.

18. LEE, D.; KIM, H.; PARK, S.; WOO, E.; JEONG, H. 2003. Gram-positive bacteria specific properties of silybin derived from Silybum marianum. Arch. Pharm. Res. 26(8):597-600.

19. MAKABIR, P. 1990. Especies Vegetales Promisorias de países del Convenio Andrés Bello. Bogotá. Editorial Convenio Andrés Bello. p.567-568.

20. MARTÍNEZ, M.; BARREIRO, M.; MOREJON, Z.; RUBALKABA, Y. 2000. Actividad antimicrobiana de un extracto fluido al $80 \%$ de Schinus terebithifolius RADDI COPPAL. Rev. Cubana Plantas Medicinales. 5(1):23-25.

21. MARTÍNEZ, M. 1996. Ausencia de actividad antimicrobiana de un extracto acuoso liofilizado de Áloe vera (sábila). Rev. Cubana Plant Med. 1(3):18-20

22. MISRA, L.; LAATSCH, H. 2000. Triterpenoids, essential oil and photooxidative 28-13-lactonization of oleanolic acid from Lantana camara. Phytochem. 5:969-974.

23. MOLINA, G.; PEREZ, A.; BECERRIL, P.; SALAZAR, R. 2007. Evaluation of the flora of Northern Mexico for in vitro antimicrobial and antituberculosis activity. J. Ethnopharmacology. 109:435-441.

24. NASCIMENTO, G.; LOCATELLI, J.; FREITAS, P.; SILVA, G. 2000. Antibacterial activity of plant extracts and phytochemicals on antibiotic resistant bacteria. Braz. J. Microbiol. 31:247-256.

25. ORGANIZACIÓN MUNDIAL DE LA SALUD. 2001. Strategy to contain resistence to antimicrobial drugs. Rev. Panam. Salud Pública 10(4):284-294.

26. RAJAKARUNA, N.; CORY, H.; TOWERS, G. 2002. Antimicrobial activity of plants collected from Serpentine Outcrop in Sri Lanka. Pharmaceutical Biol. 40(3):235-244.

27. RAMÍREZ, L.; DÍAZ, M. 2007. Actividad antibacteriana de extractos y fracciones del ruibarbo (Rumex conglomeratus). Scientia et Technica. 13(33):397-400.

28. ROJAS, J.; OCHOA, V.; OCAMPO, S.; MOÑOZ, J. 2006. Screening for antimicrobial activity of ten medicinal plants used in Colombian folkloric medicine: A possible alternative in the treatment of non-nosocomial infections. BMC complement. Altern. Med. 6(2):2-10.
29. SALEH, M.; KAMEL, A.; LI, X.; SWARAY, J. 1999. Antibacterial triterpenoids isolated from Lantana camara. Formerly International J. Pharmacognosy. 37(1):63-66.

30. SAMY, R.; IGNACIMUTHU, S. 2000. Antibacterial activity of some folklore medicinal plants used by tribals in Western Ghats of India. J. Ethnopharmacol. 69:63-71.

31. SÁNCHEZ, M. 2006. Extracción de aceites esenciales. II Congreso Internacional de Plantas Medicinales y Aromáticas, U. N.I de Colombia (Palmira). Disponible en http://www.docstoc.com/docs/21155351/UniversidadNacional-de-Colombia-Sede-Palmira-Extracci\%C3 \%83\%C2\%B3n-De-Aceites. (con acceso 14/01/10).

32. SÁNCHEZ, M. 1998. Manual de Procedimientos en Bacteriología Clínica. Ed. Asesores Biobacter Ltda. $5^{a}$ ed. p.116-117.

33. SAN MARTÍN, B.; BRAVO, B.; BORIE, C. 2005. Evaluación de la resistencia antimicrobiana en ganado bovino en Chile, utilizando $E$. coli como bacteria indicadora. Arch. Med. Vet. (Chile). 37(2):117-123.

34. SHARMA, B.; KUMAR, P. 2009. Bioefficacy of Lantana camara l. against some human pathogens. Indian J Pharm Sci. 71(5):589-593

35. SOTO, L. 2003. Resistencia bacteriana. Rev. Cubana Med. Milit. 32(1):44-48.

36. STRUTHERS, K.; WESTRAN, R. 2005. Bacteriología clínica. Ed. Masson S. A. p.192.

37. UDAYAKUMAR, R.; HAZZENA, B. 2002. Antimicrobial studies of some selected medicinal plants. Ancient Sci. Life. 21:230-234.

38. VALSARAJ, R.; PUSHPANGADAN, P.; SMITT. U.; ADERSEN. A.; NYMAN, U. 1997. Antimicrobial screening of selected medicinal plants from India. J. Ethnopharmacol. 5(8):75-83.

39. VLACHOS, V.; CRICHLEY, A.; VONHOLLY, A. 1997. Antimicrobial activity of extracts from selected southern African marine algae. South Afr. J. Science. 93:328-332.

40. VLACHOS, V.; CRICHLEY, A.; VONHOLLY, A. 1996. Establishment of protocol for testing antimicrobial activity in southern African macroalgae. Microbios. 88:115-123.

Recibido: Abril 3 de 2010

Aceptado: Octubre 14 de 2010 